\title{
ROLE OF DIAGNOSTIC LAPAROSCOPY IN NONSPECIFIC CHRONIC ABDOMINAL PAIN: EXPERIENCE OF 100 CASES
}

Abhay Kumar¹, M. Yousuf Sarwar², Nawal Kishor Pandey ${ }^{3}$

\section{HOW TO CITE THIS ARTICLE:}

Abhay Kumar, M Yousuf Sarwar, Nawal Kishor Pandey. "Role of diagnostic laparoscopy in nonspecific chronic abdominal pain: experience of 100 cases". Journal of Evolution of Medical and Dental Sciences 2013; Vol2, Issue 48, December 02; Page: 9361-9366.

ABSTRACT: BACKGROUND: Chronic idiopathic pain syndromes are among the most challenging and demanding conditions to treat across the whole age spectrum. Potentially it can be unrewarding for both the patients and the medical team. Patients with chronic abdominal pain (CAP) can undergo numerous diagnostic tests with failure to detect any structural or biochemical abnormality. This study was undertaken to assess the diagnostic and therapeutic role of laparoscopy in patients with unexplained chronic abdominal pain (UCAP). PATIENTS AND METHODS: Diagnostic laparoscopy was performed for 100 patients with UCAP not diagnosed by usual clinical examination and investigations. The pain in all patients was of unclear etiology despite all the investigative procedures. All patients were subjected to laparoscopic evaluation for their conditions. The findings and outcomes of the laparoscopy were recorded and analyzed. RESULTS: UCAP is common in females $(62 \%)$ than in males. The most frequent laparoscopic findings detected were abdominal adhesions (30\%), followed by pelvic inflammatory disease (25\%), abdominal tuberculosis (12\%), chronic appendicitis (8\%), mesenteric lymphadenitis (5\%) and diverticulosis (2\%). In 18\% of cases no identifiable cause could be found. Follow after 2 months revealed pain relief in $84 \%$ irrespective of cause of pain. CONCLUSION: Laparoscopy is an effective diagnostic and therapeutic modality in the management of patients with chronic abdominal pain.

KEYWORDS: Chronic abdominal pain, diagnostic laparoscopy, chronic appendicitis, adhesions

INTRODUCTION: Chronic Abdominal pain (CAP) is a common complaint of patients seeking a primary care physician, it is a leading reason for referral to a gastroenterologist and the 4th frequent chronic pain syndrome in the general population, it represent about $13 \%$ of all surgical admissions. (1) Chronic pelvic pain (CPP) is estimated to have a prevalence of $3.8 \%$ in Women of reproductive age and it is the reason for $10 \%$ of all out patients visits to gynecologist as well as being responsible for approximately $40 \%$ of laparoscopy by gynecologists(2) . In chronic abdominal pain more than $40 \%$ of the patients have no specific etiological diagnosis made at the end of diagnostic workup and called as unexplained chronic abdominal pain (UCAP) .(3) UCAP is associated with poor quality of life (4) and significant levels of depressive symptoms.(5).

Many organic and functional diseases can cause abdominal pain. The most common organic conditions include intestinal adhesions, (6,7) biliary causes, (8,9) and appendicular causes, (10) while functional conditions include irritable bowel disease, (11) functional dyspepsia, (12) and various motility disorders. (13) Abdominal wall pain is also common and frequently mistaken for visceral pain. $(14,15)$ After ruling out common diseases by careful investigations, many patients are still undiagnosed and represent a major diagnostic challenge to the surgeon. (16).

With the introduction of laparoscopic surgery, a new tool has been added to our knowledge. The use of this new technology in the diagnosis and management of chronic abdominal pain has 


\section{ORIGINAL ARTICLE}

been tried in previous studies. (17- 19) Laparoscopy can identify abnormal findings and improve the outcome in a majority of patients with chronic abdominal pain, as it allows surgeons to see and treat many abdominal conditions that cannot be diagnosed otherwise. (18) It is a safe and effective tool and can establish the etiology and allows for appropriate interventions in such cases. (20) Abdominal adhesions are the most likely findings, especially in patients with a past history of abdominal operations. (21) Other findings such as appendiceal pathology, hepatobiliary causes, and endometriosis can be discovered and dealt with. (17) However, the role of laparoscopy in chronic abdominal pain is still debated by some authors who deny its value in adhesiolysis and consider it controversial and not evidence-based, and therefore, do not recommend it as a treatment for adhesions in patients with chronic abdominal pain. $(22,23)$ In the present study we aim to evaluate the use of the laparoscope in the diagnosis and management of patients with chronic abdominal pain.

Laparoscopic surgery is a method in which the peritoneal cavity can be visualised without making large surgical incisions.(24) It has modified the management of many surgical diseases.(25) Diagnostic laparoscopy is now accepted as the preferred primary approach to many disease processes.(26).

PATIENTS AND METHODS: Total 100 patients with history of nonspecific abdominal pain for 6 months were included in this prospective study. Study was conducted in the department of surgery VCSGGMS \& RI between March 2010 to March 2013. The pain in all patients was of unclear etiology despite all the investigative procedures. Patients under 16 yrs of age and having previous laparotomy were excluded from the study. After taking history and clinical examination, relevant blood investigations, x-ray abdomen and ultrasound were performed. A proforma was used to record the socio-demographic data of the patients along with clinical findings, investigations, laparoscopic findings, diagnosis, and complications. All patients were subjected to laparoscopic evaluation for their conditions. The findings and outcomes of the laparoscopy were recorded and analyzed. Outcome measures included diagnosis made, duration of surgery, duration of hospital stay and postoperative complications. Data was analysed by using SPSS Version 15. Descriptive statistics like frequency, percentage, mean etc. were calculated.

RESULTS: Mean age of the patients was $34.42 \pm 2.56$ years. More than half of the patients studied were females $(62 \%)$. The mean duration of pain was $9.5 \pm 2.4$ months. The most common site of pain was the periumbilical region (35\%) followed by the right lower abdominal quadrant (25\%). All patient characteristics are summarized in table 1. 


\section{ORIGINAL ARTICLE}

\begin{tabular}{|l|c|}
\hline \multicolumn{1}{|c|}{ Characters } & Values \\
\hline Mean age & $34.42 \pm 2.56$ \\
\hline Females & $62 \%$ \\
\hline Males & $38 \%$ \\
\hline Site of pain & $35 \%$ \\
\hline Periumbilical & $25 \%$ \\
\hline Right lower quadrant & $20 \%$ \\
\hline Left lower quadrant & $12 \%$ \\
\hline Right upper quadrant & $8 \%$ \\
\hline Left upper quadrant & Table 1: Patients characteristics \\
\hline
\end{tabular}

The mean operative time was $55 \pm 15$ minutes. There was no case converted to open procedures. Out the 100 patients with chronic abdominal pain, a definitive diagnosis was established in 82 patients (82\%), while no identifiable cause could be reached in $18(18 \%)$.

The most common laparoscopic findings were adhesions (30\%). Other findings included pelvic inflammatory disease (25\%), abdominal tuberculosis (12\%), chronic appendicitis (8\%), mesenteric lymphadenitis (5\%) and diverticulosis. (2 \%) Table 2 summarizes the laparoscopic diagnoses assigned to all patients.

\begin{tabular}{|l|c|}
\hline \multicolumn{1}{|c|}{ Findings } & Values \\
\hline Operative time (mean \pm SD) & $55 \pm 15$ minutes \\
\hline Laparoscopic findings & $30 \%$. \\
\hline Adhesions & $25 \%$ \\
\hline $\begin{array}{l}\text { Pelvic inflammatory } \\
\text { disease }\end{array}$ & $12 \%$ \\
\hline Abdominal tuberculosis & $8 \%$ \\
\hline Chronic appendicitis & $5 \%$ \\
\hline Mesenteric lymphadenitis & $2 \%$ \\
\hline Diverticulosis & $1.8 \pm 1.4$ days \\
\hline Post operative hospital stay & Table 2: Operative findings of patients \\
\hline
\end{tabular}

Laparoscopic management included adhesiolysis (26\%), lymph node or peritoneal biopsy (17\%) and appendectomy (8\%), 31 patients had no interventions performed.

Mean postoperative hospital stay was $1.8 \pm 1.4$ days. In most cases no postoperative complications had been reported except in five cases (two cases showed bleeding and three cases showed infection). The bleeding could be dealt with through electrocautery and infection was dealt with proper antibiotics.

After 2 months of follow up 40 patients had complete relief from pain while 46 patients had decrease in pain score. Rest 14 patients showed no improvement in pain. 


\section{ORIGINAL ARTICLE}

DISCUSSION: Chronic abdominal pain, defined as pain reported for a minimum period of 6 months and is affecting the daily life activities of the patients. Diagnosis and treatment plane in patients with CAP is usually difficult and frustrating. When no cause can be identified it is called unexplained chronic abdominal pain (UCAP). It is one of the most common surgical symptoms, and among the most challenging problems facing the physician (27). Abdominal pain was the third most common pain complaint of individuals enrolled in a large health maintenance organisation (28).

One hundred patients with chronic abdominal pain of no obvious cause or uncertain diagnosis were evaluated laparoscopically, to determine the underlying cause of pain and possible management. Laparoscopic examination revealed normal abdominal anatomy with no pathologic lesion in 18 patients (18\%) whereas in 82 patients (82\%) some abdominal or pelvic pathology was found. This figure coincides with the laparoscopic study of Marana and his coworkers (28).

The most frequent abdominal pathology detected in our study were abdominal adhesions in 30\%. Tiwari and Peters (29) and Di lorenzo and colleagues (30), reported an incidence of 31.5\% and $18.6 \%$ respectively. It has been found that pain is located in the area of adhesions in $90 \%$ of cases, although there is no correlation between the severity of pain and extent of adhesions (31). Adhesions will cause CAP if it restrict the mobility or distensibility of abdominal organs especially the bowel (32).

Pelvic inflammatory disease (PID) was the second most common cause of UCAP and incidence was $25 \%$. Among females it was the most common cause (40.3\%). High incidence of PID in our study was consistent with the findings of Gowri and Krolikowski.(33) Abdominal tuberculosis was $12 \%$ of patients and the incidence was higher than that of western studies this reflects higher incidence of tuberculosis in developing countries.

In our study chronic appendicitis was the cause of nonspecific CAP in 8 patients (8\%) all were managed by laparoscopic appendectomy, complete relief of pain was observed in all. Raymond and his colleagues (34) reported $15.7 \%$ chronic appendicitis, with improvement of pain in $90 \%$ of the patients. Mesenteric lymphadenitis was found in 5\% of cases and may be due to infectious cause of bowel like colitis, gastroenteritis or enteric fever.

We found that in a selected patient group, laparoscopic evaluation of unexplained chronic abdominal pain is usually associated with a positive outcome (86\%) in terms of less or no pain, after two months of laparoscopy. This finding is justified in many previous studies, (17 and 20) however; the role of laparoscopy from the therapeutic point of view is still ignored by some authors, especially its role in adhesiolysis. $(22,23)$

CONCLUSIONS: Diagnostic laparoscopy in CAP with unknown etiology is a significant examination tool which increases our understanding of many underlying abdominal disorders. However it should be undertaken only after a complete diagnostic evaluation has been carried out. It is not only diagnostic but also considerably therapeutic irrespective of etiology of pain.

\section{REFERENCES:}

1. John, R.D.; Gary, W.V. and Laurie, H.: What could be causing chronic abdominal pain?. Postgraduate Medicine.1999;106 (3) : 1 - 8.

2. Propora, M.G. \& Gomel, V.: The role of laparoscopy in the management of pelvic pain in women of reproductive age. Fertility \& sterility.1997; 68(5): 765-779. 


\section{ORIGINAL ARTICLE}

3. El-labban GM, Hokkam EN. The efficacy of laparoscopy in the diagnosis and management of chronic abdominal pain. J Minim Access Surg. 2010;6:95-9.

4. Ferrell BR. The impact of pain on quality of life: A decade of research. Nurs Clin North Am.1995;30:609-24.

5. Magni G, Rossi MR, Rigatti-Luchini S, Merskey H. Chronic abdominal pain and depression. Epidemiologie findings in the United States. Hispanic health and nutrition examination survey. Pain.1992;49:77-85.

6. Peters AA, Van den Tillaart SA. The difficult patient in gastroenterology: Chronic pelvic pain, adhesions, and sub occlusive episodes. Best Pract Res Clin Gastroenterol. 2007;21:445-63.

7. Van Goor H. Consequences and complications of peritoneal adhesions. Colorectal Dis. 2007;9:25-34.

8. Dumont RC, Caniano DA. Hypokinetic gallbladder disease: A cause of chronic abdominal pain in children and adolescents. J Pediatr Surg. 1999;34:858-61.

9. Johnson CD. ABC of the upper gastrointestinal tract. Upper abdominal pain: Gall bladder. BMJ.2001;323:1170-3.

10. Fayez JA, Toy NJ, Flanagan TM. The appendix as the cause of chronic lower abdominal pain. Am J Obstet Gynecol. 1995;172:122-3.

11. Mertz HR. Irritable bowel syndrome. N Engl J Med. 2003;349:2136-46.

12. Tack J, Lee KJ. Pathophysiology and treatment of functional dyspepsia. J Clin Gastroenterol.2005;39:S211-6.

13. Abell TL, Werkman RF. Gastrointestinal motility disorders. Am Fam Physician. 1996;53:895902.

14. Lindsetmo RO, Stulberg J. Chronic abdominal wall pain-a diagnostic challenge for the surgeon. Am J Surg. 2009;198:129-34.

15. Costanza CD, Longstreth GF, Liu AL. Chronic abdominal wall pain: Clinical features, health care costs, and long-term outcome. Clin Gastroenterol Hepatol. 2004;2:395-9.

16. Galili O, Shaoul R, Mogilner J. Treatment of Chronic Recurrent Abdominal Pain: Laparoscopy or Hypnosis? J Laparoendosc Adv Surg Tech A. 2009;19:93-6.

17. Salky BA, Edye MB. The role of laparoscopy in the diagnosis and treatment of abdominal pain syndromes. Surg Endosc. 1998;12:911-4.

18. Klingensmith ME, Soybel DI, Brooks DC. Laparoscopy for chronic abdominal pain. Surg Endosc.1996;10:1085-7.

19. Mueller MD, Tschudi J, Herrmann U, Klaiber CH. An evaluation of laparoscopic adhesiolysis in patients with chronic abdominal pain. Surg Endosc. 1995;9:802-4.

20. Onders RP, Mittendorf EA. Utility of laparoscopy in chronic abdominal pain. Surgery.2003;134:552-4.

21. Szomstein S, Lo Menzo E, Simpfendorfer C, Zundel N, Rosenthal RJ. Laparoscopic lysis of adhesions. World J Surg. 2006;30:535-40.

22. Ikard RW. There is no current indication for laparoscopic adhesiolysis to treat abdominal pain.South Med J. 1992;85:939-40.

23. Swank DJ, Swank-Bordewijk SC, Hop WC, van Erp WF, Janssen IM, Bonjer HJ, et al. Laparoscopic adhesiolysis in patients with chronic abdominal pain: A blinded randomised controlled multi-centre trial.Lancet. 2003;361:1247-51. 


\section{ORIGINAL ARTICLE}

24. All sold out Internet Solution: Laparoscopy. 1995-2001. Available from URL: http://www.healthnmore.org/laprosc.htm.

25. Yousaf M, Hosuy MA. Small bowel obstruction after laparoscopic inguinal hernia repair. J Coll Physicians Surg Pak. 2001;11:721-2.

26. Gharam A, Henley C, Mobley J. Laparoscopic evaluation of acute abdominal pain. J Laparoendosc

27. Scmidbauer, S. and Hallfeldt, K. : Laparoscopic adhesiolysis in patients with chronic abdominal pain. Surgery 2001; 129(4) : 513- 4.

28. Marana, R.; Paielli, FV.; Muzii, L and Mancusol, J: The role of laparoscopy in evaluation of chronic abdominal pain. Minerva Gynecol. 1993 ; Jun 45(6):281-6.

29. Iwari, A. and Peters, J.C.: Laparoscopic adhesiolysis in patients with chronic abdominal pain.Lancet.2003; 28(361): 2243-2247.

30. Di lorenzo, N. ; Coscarella, G. ; Lirosi, F. ; Faraci, L. and Rossi, P. : Impact of laparoscopic surgery in the treatment of chronic abdominal pain syndrome.Chir Ital. 2002 ; 54(3) : 367- 78.

31. Mahawar, K.K.: Laparoscopic adhesiolysis in patients with chronic abdominal pain. Lancet (England). 2003; 361(9376) : 2243-4.

32. Swank, D.J.; Van Erp, W.F.; Repelaer, O. J.; Hop,W. C. and Bonjer,H.J. :A prospective analysis of predictive factors on the results of laparoscopic adhesiolysis in patients with chronic abdominal pain. Surg Laparosc Endosc. 2003; 13(2): 88-94.

33. Gowri; V \& Krolikowski, A.: Chronic pelvic pain. Laparoscopic and cystoscopic findings. Saudi. Medical.J.2001; 22(9): 769-70.

34. Raymond, P. o.; Elizabeth, A. M. and Cleveland, O.H. : Role of laparoscopy in patients with chronic abdominal pain and assessment of late outcome. Digestive disease week. 2001;23(4):241-46.

\section{AUTHORS:}

1. Abhay Kumar

2. M. Yousuf Sarwar

3. Nawal Kishor Pandey

\section{PARTICULARS OF CONTRIBUTORS:}

1. Assistant Professor, Department of Surgery, VCSGGMS \& RI, Srinagar, Uttarakhand, India.

2. Assistant Professor, Department of Anatomy, Katihar Medical College, Katihar, Bhiar, India.

3. Professor, Department of Anatomy, Katihar Medical College, Katihar, Bhiar, India.

\section{NAME ADRRESS EMAIL ID OF THE} CORRESPONDING AUTHOR:

Dr. Abhay Kumar,

Department of Surgery,

VCSGGMS \& RI, Srinagar - 246174,

Uttarakhand, India.

Email - aabhaaykumaar@rediffmail.com

Date of Submission: 15/11/2013.

Date of Peer Review: 16/11/2013.

Date of Acceptance: 21/11/2013.

Date of Publishing: 27/11/2013 